\title{
FIT \& STRONG! PLUS: DESCRIPTIVE DEMOGRAPHIC AND RISK CHARACTERISTICS IN A COMPARATIVE EFFECTIVENESS TRIAL FOR OLDER AFRICAN-AMERICAN ADULTS WITH OSTEOARTHRITIS
}

\author{
M. L Fitzgibbon ${ }^{1,2,3}$, L. Tussing-Humphreys ${ }^{1,3,4}$, L. Schiffer ${ }^{3}$, R. Smith-Ray ${ }^{3,5}$, A.D. Demott ${ }^{3,6}$, M. Martinez ${ }^{3,6}$, \\ M.L. Berbaum ${ }^{1,3}$, G.M. Huber ${ }^{7}$, S.L. Hughes ${ }^{3,6}$
}

\begin{abstract}
Objectives: The prevalence of osteoarthritis (OA) has increased in the US. We report on a comparative effectiveness trial that compares Fit \& Strong!, an existing evidence-based physical activity (PA) program, to Fit \& Strong! Plus, which combines the Fit \& Strong! intervention with a weight management intervention. Methods: Participants included 413 overweight/obese (BMI $25-50 \mathrm{~kg} / \mathrm{m}^{2}$ ) adults with lower extremity (LE) OA. The majority of the sample was African-American and female. Both interventions met 3 times weekly for 8 weeks. Primary measures included diet and weight. Results: The baseline mean BMI for all participants was $34.8 \mathrm{~kg} / \mathrm{m}^{2}$, percentage of calories from fat was high, and self-reported PA was low. Discussion: This sample of overweight/obese African-American adults had lifestyle patterns at baseline that were less than healthful, and there were differences between self-report and performance-based measures as a function of age.
\end{abstract}

Key words: Weight management, obesity, older adults, physical activity.

\section{Purpose}

Arthritis and related rheumatic conditions, including osteoarthritis (OA), affect approximately 50 million or $22 \%$ of the adult United States (US) population (1), and the majority of affected individuals are older adults. African Americans with OA have higher rates of inactivity and functional limitations than non-Hispanic whites (2-4), and African-American women with OA have approximately twice the rate of disability compared to non-Hispanic whites (5). Risk factors for OA include genetics, female sex, and obesity (6), and obesity is a strong risk factor for the incidence and progression of knee OA $(7,8)$. Unfortunately, the prevalence of obesity has increased significantly since the 1980s, with AfricanAmerican women $\geq 60$ years having the highest rates compared to non-Hispanic white women (57.5\% vs. $38.2 \%)(9-13)$.

1. University of Illinois Cancer Center, Chicago, IL 60612; 2. Department of Pediatrics, University of Illinois at Chicago, Chicago, IL 60612; 3. Institute for Health Research and Policy, School of Public Health, University of Illinois at Chicago, Chicago, IL, 60608; 4. Department of Medicine, University of Illinois at Chicago, Chicago, IL 60612; 5. Health Analytics, Research and Reporting, Walgreen Co., Deerfield, IL, 60015; 6. Center for Research on Health and Aging, University of Illinois at Chicago, Chicago, IL 60608; 7. Physical Therapy and Human Movement Sciences, Northwestern University, Chicago, IL, 60611

Corresponding Author: Marian L. Fitzgibbon, PhD, University of Illinois at Chicago, 486 Westside Research Office Building, 1747 W. Roosevelt Rd., Chicago, IL, 60608, Email: mlf@uic.edu, Phone: 312-996-0146
Obese individuals who have OA are usually advised to lose weight (14-16). Several studies support the combination of physical activity (PA) and weight management as central to the reduction of knee pain and limitations in mobility $(17,18)$, and several randomized controlled trials (RCTs) have tested the combined impact of modest weight loss with regular moderate PA compared to either PA or diet/weight management alone $(17,19-22)$. These studies highlight a need to test relatively simple, easily replicable evidence-based programs that combine both PA and weight management for adults with OA and to test these interventions with disadvantaged populations that have consistently higher rates of OA and obesity, such as African-American women $(1,23)$. To address this need, our team developed and is testing Fit \& Strong! Plus.

Fit \& Strong! Plus combines interventions from two successful RCTs that have shown improvements in PA (Fit \& Strong!) and weight management (the Obesity Reduction Black Intervention Trial, ORBIT) (24-26). The Fit \& Strong! intervention and its evidence base are described in detail elsewhere (27-29). ORBIT is a 6-month weight loss and PA intervention targeting African-American women that was successful in reducing weight by $3.0 \mathrm{~kg}$ in the intervention group, on average (25). In 2012, we received funding to test the comparative effectiveness of customary Fit \& Strong! vs. the new Fit \& Strong! Plus version using an RCT. The details of the trial 
design are published elsewhere (30).

\section{Methods}

\section{Design}

The Fit \& Strong! Plus trial is a randomized comparative effectiveness trial that is testing whether Fit \& Strong! Plus produces significantly better results than standard Fit \& Strong! on weight, dietary intake, PA, physical performance, OA-associated symptoms of LE pain and stiffness, anxiety / depression, and selfefficacy for weight loss and exercise among overweight / obese adults with OA. The project was approved by the Institutional Review Board at the University of Illinois at Chicago (UIC), and all participants gave written informed consent. The trial is registered at clinicaltrials. gov (NCT03180008).

\section{Setting}

Both interventions were conducted at local community sites.

\section{Subjects}

Participants were randomly assigned to Fit \& Strong! $(\mathrm{n}=210)$ or Fit \& Strong! Plus $(\mathrm{n}=203)$ and are being followed for 18 months.

\section{Interventions}

Both Fit \& Strong! and Fit \& Strong! Plus are conducted in 90-minute sessions 3 times per week over an 8-week period. The first 60 minutes of both interventions consist of stretching, low-impact aerobics, and strengthening exercises with a consistent focus on lower extremity muscles. The interventions diverge in the 30-minute health education component at the end of the session. The health education component of Fit \& Strong is designed to build self-efficacy (SE) related to managing pain and OA symptoms through PA, while Fit \& Strong! Plus also incorporates SE for dietary weight management behaviors.

\section{Measures}

Anthropometrics: Height was measured using a portable stadiometer (Seca, United Kingdom), and weight was measured using a calibrated digital scale (Tanita Worldwide). Both height and weight were measured twice. If the two measurements were $>0.5 \mathrm{~cm}$ or $>0.2$ $\mathrm{kg}$ apart, a third measurement was taken, and the mean of the two closest measurements was used. BMI was calculated as weight $(\mathrm{kg})$ divided by height $(\mathrm{m})$ squared.
To assess body composition change, we measured waist circumference twice using a Gulick 150-centimeter anthropometric tape (Country Technology, Inc.; Gays Mills, WI, USA). If the two waist measurements were $>1$ $\mathrm{cm}$ apart, a third measurement was taken, and the mean of the two closest measurements was used.

\section{Dietary intake}

We used the Block 2005 Food Frequency Questionnaire (FFQ) to assess dietary intake. The FFQ, which inquires about approximately 110 food items, was designed to estimate habitual intake of an array of nutrients and food groups (31). Using data from the FFQ, participants' diet quality was calculated using the Healthy Eating Index2010 (HEI) (32), which measures adherence to the 2010 Dietary Guidelines for Americans (DGA).

\section{Physical Activity}

PA was assessed using the Physical Activity Scale for the Elderly (PASE) (33), a valid and reliable self-report measure for older adults, with a higher score indicating greater self-reported physical activity.

\section{Performance measures}

Lower extremity (LE) strength was measured using the 30-second Chair Stand, which tests the number of full stands from a seated position a person can complete in 30 seconds with folded arms (34). Mobility was assessed using the 6-minute Walk Test, which measures functional exercise capacity (35-37).

\section{OA Symptoms}

The Western Ontario and McMaster Universities Arthritis Index (WOMAC) was used to assess OA symptoms of stiffness and pain in the hip and knee joints during daily activities and the degree to which physical functioning is affected by arthritis.

\section{Depression and anxiety}

These outcomes were measured using the GERI-AIMS, a version of the Arthritis Impact Measurement Scale that was adapted for use with an elderly population (38).

\section{Self Efficacy}

We assessed weight-related SE using the Weight Efficacy Lifestyle Questionnaire (WEL), a 20-item measure that assesses confidence to manage eating in an array of situations (39). 
Table 1

Participant characteristics at baseline

\begin{tabular}{|c|c|c|c|c|c|c|}
\hline & \multicolumn{2}{|c|}{ F\&S! Plus N=203 } & \multicolumn{2}{|c|}{$F \& S ! N=210$} & \multicolumn{2}{|c|}{ All N=413 } \\
\hline & Mean or $\%$ & SD or $\mathbf{N}$ & Mean or $\%$ & SD or $\mathbf{N}$ & Mean or $\%$ & SD or $\mathbf{N}$ \\
\hline Age, y & 67.7 & 6.0 & 68.1 & 5.8 & 67.9 & 5.9 \\
\hline \multicolumn{7}{|l|}{ Sex } \\
\hline Female & $87 \%$ & 177 & $85 \%$ & 178 & $86 \%$ & 355 \\
\hline Male & $13 \%$ & 26 & $15 \%$ & 32 & $14 \%$ & 58 \\
\hline \multicolumn{7}{|l|}{ Race } \\
\hline Black or African American, not Hispanic & $92 \%$ & 187 & $92 \%$ & 193 & $92 \%$ & 380 \\
\hline White, not Hispanic & $4 \%$ & 8 & $4 \%$ & 9 & $4 \%$ & 17 \\
\hline Hispanic & $1 \%$ & 3 & $1 \%$ & 2 & $1 \%$ & 5 \\
\hline Multiracial/other & $2 \%$ & 5 & $3 \%$ & 6 & $3 \%$ & 11 \\
\hline Education, y & 14.3 & 1.9 & 14.1 & 2.0 & 14.2 & 1.9 \\
\hline Not HS graduate & $4 \%$ & 9 & $7 \%$ & 15 & $6 \%$ & 24 \\
\hline HS graduate/GED & $13 \%$ & 27 & $16 \%$ & 34 & $15 \%$ & 61 \\
\hline Some college or technical school & $45 \%$ & 91 & $40 \%$ & 84 & $42 \%$ & 175 \\
\hline College graduate & $37 \%$ & 76 & $37 \%$ & 77 & $37 \%$ & 153 \\
\hline Employed full or part-time & $15 \%$ & 30 & $11 \%$ & 23 & $13 \%$ & 53 \\
\hline \multicolumn{7}{|l|}{ Marital status } \\
\hline Married or member of unmarried couple & $26 \%$ & 52 & $26 \%$ & 54 & $26 \%$ & 106 \\
\hline Divorced or separated & $34 \%$ & 70 & $39 \%$ & 82 & $37 \%$ & 152 \\
\hline Widowed & $24 \%$ & 48 & $20 \%$ & 43 & $22 \%$ & 91 \\
\hline Never married & $16 \%$ & 33 & $15 \%$ & 31 & $16 \%$ & 64 \\
\hline Income, median & 25,000 & & 25,000 & & 25,000 & \\
\hline \multicolumn{7}{|l|}{ Health insurance ${ }^{b}$} \\
\hline Medicare & $67 \%$ & 136 & $70 \%$ & 147 & $69 \%$ & 283 \\
\hline Medicaid & $16 \%$ & 33 & $18 \%$ & 38 & $17 \%$ & 71 \\
\hline Private/supplemental & $44 \%$ & 89 & $40 \%$ & 83 & $42 \%$ & 172 \\
\hline Chronic conditions, of $17^{c}$ & 2.8 & 1.6 & 3.0 & 1.7 & 2.9 & 1.6 \\
\hline Weight, kg & 93.0 & 16.6 & 93.5 & 16.0 & 93.3 & 16.3 \\
\hline BMI, $\mathrm{kg} / \mathrm{m}^{2}$ & 34.7 & 5.7 & 34.9 & 5.4 & 34.8 & 5.5 \\
\hline \multicolumn{7}{|l|}{ BMI category } \\
\hline Overweight $\left(25-<30 \mathrm{~kg} / \mathrm{m}^{2}\right)$ & $21 \%$ & 43 & $19 \%$ & 39 & $20 \%$ & 82 \\
\hline Obesity class I $\left(30-<35 \mathrm{~kg} / \mathrm{m}^{2}\right)$ & $36 \%$ & 73 & $35 \%$ & 74 & $36 \%$ & 147 \\
\hline Obesity class II $\left(35-<40 \mathrm{~kg} / \mathrm{m}^{2}\right)$ & $24 \%$ & 48 & $26 \%$ & 54 & $25 \%$ & 102 \\
\hline Obesity class III $\left(\geq 40 \mathrm{~kg} / \mathrm{m}^{2}\right)$ & $19 \%$ & 39 & $20 \%$ & 43 & $20 \%$ & 82 \\
\hline Waist circumference, $\mathrm{cm}$ & 114.0 & 14.1 & 112.3 & 12.9 & 113.1 & 13.5 \\
\hline Height, $\mathrm{cm}$ & 163.8 & 7.8 & 163.6 & 7.8 & 163.7 & 7.8 \\
\hline Energy, kcal & 1606 & 700 & 1553 & 721 & 1579 & 710 \\
\hline Fat, $g$ & 72.8 & 34.4 & 68.7 & 36.3 & 70.7 & 35.4 \\
\hline Fat, $\%$ kcal & 40.6 & 6.6 & 39.2 & 7.2 & 39.9 & 6.9 \\
\hline Fiber, g & 15.2 & 7.8 & 15.2 & 7.6 & 15.2 & 7.7 \\
\hline Fiber, g/1000 kcal & 9.7 & 3.5 & 10.1 & 3.7 & 9.9 & 3.6 \\
\hline Healthy Eating Index-2010 & 65.9 & 9.8 & 66.7 & 11.1 & 66.3 & 10.5 \\
\hline
\end{tabular}


Table 1 (continued)

Participant characteristics at baseline

\begin{tabular}{|c|c|c|c|c|c|c|}
\hline & \multicolumn{2}{|c|}{ F\&S! Plus N=203 } & \multicolumn{2}{|c|}{$F \& S ! N=210$} & \multicolumn{2}{|c|}{ All $N=413^{a}$} \\
\hline & Mean or $\%$ & SD or $\mathbf{N}$ & Mean or $\%$ & SD or $\mathbf{N}$ & Mean or $\%$ & SD or $\mathbf{N}$ \\
\hline \multicolumn{7}{|l|}{ HEI-2010 category } \\
\hline Poor $(0-50)$ & $6 \%$ & 11 & $10 \%$ & 21 & $8 \%$ & 32 \\
\hline Needs improvement (51-80) & $89 \%$ & 176 & $82 \%$ & 166 & $86 \%$ & 342 \\
\hline Good (81-100) & $5 \%$ & 10 & $8 \%$ & 16 & $7 \%$ & 26 \\
\hline PASE physical activity score ${ }^{\mathrm{d}}$ & 97.3 & 59.7 & 97.0 & 62.9 & 97.2 & 61.3 \\
\hline Six-minute walk, m & 358.8 & 94.0 & 353.9 & 100.1 & 356.3 & 97.1 \\
\hline Chair stands in $30 \mathrm{sec}$ & 8.7 & 3.4 & 8.8 & 3.7 & 8.7 & 3.6 \\
\hline WOMAC global score (0-96) & 26.3 & 17.7 & 27.3 & 17.1 & 26.8 & 17.4 \\
\hline Pain subscale $(0-20)$ & 5.4 & 3.9 & 5.8 & 4.1 & 5.6 & 4.0 \\
\hline Stiffness subscale (0-8) & 3.0 & 1.8 & 3.3 & 1.7 & 3.2 & 1.7 \\
\hline Physical functioning subscale (0-68) & 17.8 & 12.9 & 18.2 & 12.8 & 18.0 & 12.9 \\
\hline Anxiety / depression $(0-10)^{\mathrm{f}}$ & 2.5 & 1.7 & 2.5 & 1.7 & 2.5 & 1.7 \\
\hline Weight efficacy lifestyle (WEL) total score $(0-180)^{g}$ & 137.0 & 32.3 & 131.2 & 33.3 & 134.1 & 32.9 \\
\hline Self-efficacy for exercise $(1-10)^{g}$ & 7.7 & 1.9 & 7.6 & 2.0 & 7.6 & 2.0 \\
\hline
\end{tabular}

\section{Statistical Analyses}

We tested for differences in participant characteristics between randomization groups at baseline using t-tests for most continuous variables, Wilcoxon rank tests for income and number of chronic conditions, and chi-square tests for categorical variables. We also examined differences in anthropometrics, diet, physical activity, performance measures, WOMAC OA index, anxiety/depression, and self-efficacy by age ( $<70$ vs $\geq$ 70 years) using t-tests and chi-square tests. We explored associations with diet quality, PA, and physical performance using linear regression models with multiple covariates. SAS v 9.4 was used for all analyses.

\section{Primary Results}

This study met its target recruitment goal of 400 subjects. We randomized 413 individuals: 203 to standard Fit \& Strong! and 210 to Fit \& Strong! Plus. Table 1 reflects the baseline demographic characteristics. As we anticipated in designing the study, our sample was primarily African-American and representative of the racial and ethnic distribution of older adults in the neighborhoods surrounding the participating Chicago Park District sites. As measured by the Block 2005 FFQ, participants reported a mean energy intake of 1579 (SD $=710$ ) calories, the mean percentage of calories from fat was 39.9 ( $\mathrm{SD}=6.9 \%)$, and the mean HEI total score was 66.3 out of a possible 100, which is in the "needs improvement" range, but is consistent with the HEI2010 total score reported by the USDA for a nationally representative sample of adults that were 65 years and older (https: / / www.cnpp.usda.gov/ sites / default / files / healthy_eating_index/HEI89-90report.pdf; https: / / www.cnpp.usda.gov/sites / default/ files/healthy_eating_ index/HEI-2010-During-2011-2012-Oct21-2016.pdf).

The mean score on the PASE (33) was 97.2 $(\mathrm{SD}=61.3)$, which is lower than the mean scores of $169.3(\mathrm{SD}=88.2)$ reported by Skou and colleagues (40) and 131.4 (SD = 71.1) by Martin and colleagues (41) in work with older adult samples. Participants had a low mean score of 8.7 $(\mathrm{SD}=3.6)$ on the 30 -second chair stand as well as a low mean score of 356.3 meters $(\mathrm{SD}=97.1)$ on the six-minute walk test. On the WOMAC, participants had a mean of $5.6(\mathrm{SD}=4.0)$ on the pain subscale, $3.2(\mathrm{SD}=1.7)$ on the stiffness subscale and $18.0(\mathrm{SD}=12.9)$ on the physical functioning subscale, indicating a moderate amount of OA-related impairment at baseline. The mean score for anxiety/depression measured by the GERI-AIMS was low at $2.5(\mathrm{SD}=1.7)$. Mean overall score on weightrelated self-efficacy was $134.1(\mathrm{SD}=32.9)$, which is higher than reported for other samples of overweight/obese non-Hispanic white samples $(5,42)$. Mean self-efficacy for exercise was also relatively high: $7.6(\mathrm{SD}=2.0)$ on a $1-10$ scale. 
Table 2

Participant characteristics at baseline by age

\begin{tabular}{|c|c|c|c|c|c|}
\hline & \multicolumn{2}{|c|}{ Age $60-69 \mathrm{~N}=286^{\mathrm{a}}$} & \multicolumn{2}{|c|}{ Age $\geq 70 \quad N=127^{a}$} & \multirow[t]{2}{*}{$\mathrm{p}^{\mathrm{b}}$} \\
\hline & Mean or $\%$ & SD or $\mathbf{N}$ & Mean or $\%$ & SD or $\mathbf{N}$ & \\
\hline Weight, kg & 95.4 & 16.2 & 88.5 & 15.6 & $<.001$ \\
\hline BMI, $\mathrm{kg} / \mathrm{m}^{2}$ & 35.3 & 5.6 & 33.6 & 5.3 & .003 \\
\hline BMI category & & & & & .008 \\
\hline Overweight $\left(25-<30 \mathrm{~kg} / \mathrm{m}^{2}\right)$ & $16 \%$ & 47 & $28 \%$ & 35 & \\
\hline Obesity class I $\left(30-<35 \mathrm{~kg} / \mathrm{m}^{2}\right)$ & $36 \%$ & 104 & $34 \%$ & 43 & \\
\hline Obesity class II $\left(35-<40 \mathrm{~kg} / \mathrm{m}^{2}\right)$ & $24 \%$ & 68 & $27 \%$ & 34 & \\
\hline Obesity class III $\left(\geq 40 \mathrm{~kg} / \mathrm{m}^{2}\right)$ & $23 \%$ & 67 & $12 \%$ & 15 & \\
\hline Waist circumference, $\mathrm{cm}$ & 114.7 & 13.3 & 109.6 & 13.4 & $<.001$ \\
\hline Energy, kcal & 1607 & 755 & 1515 & 593 & .23 \\
\hline Fat, $\%$ kcal & 40.2 & 7.2 & 39.3 & 6.3 & .22 \\
\hline Fiber, g/1000 kcal & 9.6 & 3.6 & 10.6 & 3.6 & .02 \\
\hline Healthy Eating Index-2010 & 65.4 & 10.3 & 68.4 & 10.6 & .009 \\
\hline HEI-2010 category & & & & & .12 \\
\hline Poor $(0-50)$ & $9 \%$ & 25 & $6 \%$ & 7 & \\
\hline Needs improvement (51-80) & $86 \%$ & 240 & $84 \%$ & 102 & \\
\hline Good (81-100) & $5 \%$ & 14 & $10 \%$ & 12 & \\
\hline PASE physical activity score ${ }^{d}$ & 99.9 & 64.6 & 90.9 & 52.8 & .17 \\
\hline Six-minute walk, $\mathrm{m}$ & 363.9 & 94.5 & 338.8 & 101.0 & .02 \\
\hline Chair stands in $30 \mathrm{sec}$ & 8.8 & 3.4 & 8.5 & 4.0 & .40 \\
\hline WOMAC global score $(0-96)^{c}$ & 28.5 & 17.7 & 22.9 & 16.1 & .002 \\
\hline Pain subscale $(0-20)$ & 6.1 & 4.0 & 4.6 & 3.8 & $<.001$ \\
\hline Stiffness subscale $(0-8)$ & 3.3 & 1.7 & 2.7 & 1.8 & .002 \\
\hline Physical functioning subscale (0-68) & 19.1 & 13.1 & 15.6 & 12.0 & .01 \\
\hline Anxiety/depression $(0-10)^{e}$ & 2.6 & 1.7 & 2.2 & 1.7 & .01 \\
\hline Total WEL score $(0-180)^{f}$ & 130.7 & 34.9 & 141.5 & 26.7 & .002 \\
\hline Self-efficacy for exercise $(1-10)^{\mathrm{f}}$ & 7.6 & 2.0 & 7.8 & 1.9 & .19 \\
\hline
\end{tabular}

\section{Differences by Age}

As shown in Table 2, we tested for differences between younger (60-69 years) and older ( $\geq 70$ years) participants on a number of measures. Younger participants had a higher mean BMI (35.3 vs. $\left.33.6 \mathrm{~kg} / \mathrm{m}^{2}, \mathrm{p}=.003\right)$, and $23 \%$ of younger participants had Class III obesity $(\geq 40 \mathrm{~kg} /$ $\mathrm{m}^{2}$ ) compared to $12 \%$ of older participants. Consistent with their lower BMI, older participants also scored significantly higher on the HEI (mean=68.4 vs. $65.4, \mathrm{p}=$ .009 ) and consumed more fiber (10.6 vs. $9.6 \mathrm{~g} / 1000 \mathrm{kcal}, \mathrm{p}$ $=.02$ ). Mean scores on the self-reported WOMAC showed that younger participants perceived more OA-related impairment than older participants. This was evident across the pain (6.1 vs. $4.6, \mathrm{p}<.001)$, stiffness (3.3 vs. $2.7, \mathrm{p}$
$=.002$ ), and physical functioning subscales (19.1 vs. 15.6, $\mathrm{p}=.01)$. However, on the performance-based six-minute walk, younger participants had a better mean score than older participants (363.9 m vs. $338.8 \mathrm{~m}, \mathrm{p}=.02)$.

Finally, we used linear regression models with multiple covariates to explore possible predictors of diet quality, PA, and performance measures at baseline (Table $3)$. The chosen predictors explained a relatively small percentage of the variance for the HEI-2010 $\left(R^{2}=0.06\right)$ and self-reported PA $\left(R^{2}=0.07\right)$, somewhat more for chair stands in 30 seconds $\left(R^{2}=0.12\right)$ and a substantial percentage for six-minute walk distance $\left(R^{2}=0.29\right)$. None of the selected predictors were significantly associated with the HEI-2010 score at baseline. However, increased age was associated with lower self-reported PA $(b=-1.69$, 
Table 3

Predictors of diet quality, physical activity, and performance measures

\begin{tabular}{|c|c|c|c|c|c|c|c|c|c|c|c|c|}
\hline & \multicolumn{3}{|c|}{ HEI-2010 $\left(R^{2}=0.06\right)$} & \multicolumn{3}{|c|}{$\operatorname{PASE}^{a}\left(R^{2}=0.07\right)$} & \multicolumn{3}{|c|}{ 6-min walk, $\mathrm{m}\left(\mathrm{R}^{2}=0.29\right)$} & \multicolumn{3}{|c|}{ Chair stands $\left(R^{2}=0.12\right)$} \\
\hline & b & SE & $\mathbf{p}$ & $\mathbf{b}$ & SE & $\mathbf{p}$ & b & SE & $\mathbf{p}$ & $\mathbf{b}$ & SE & $\mathrm{p}$ \\
\hline Intercept & 59.3 & 9.7 & $<0.001$ & 218 & 53 & $<0.001$ & 723 & 73 & $<0.001$ & 17.5 & 3.0 & $<0.001$ \\
\hline Male & -3.00 & 1.56 & 0.05 & -0.13 & 9.13 & 0.99 & 4.24 & 12.59 & 0.74 & 0.64 & 0.52 & 0.22 \\
\hline Age, $y$ & 0.13 & 0.10 & 0.19 & -1.69 & 0.55 & 0.002 & -3.38 & 0.76 & $<0.001$ & -0.08 & 0.03 & 0.01 \\
\hline BMI, $\mathrm{kg} / \mathrm{m}^{2}$ & -0.19 & 0.11 & 0.08 & -0.69 & 0.59 & 0.24 & -4.70 & 0.82 & $<0.001$ & -0.08 & 0.03 & 0.02 \\
\hline College graduate & 0.97 & 1.10 & 0.38 & -8.40 & 6.46 & 0.19 & -5.11 & 8.89 & 0.57 & -0.05 & 0.36 & 0.88 \\
\hline Married or unmarried couple & -0.36 & 1.20 & 0.77 & 18.44 & 6.99 & 0.009 & 14.27 & 9.66 & 0.14 & 0.51 & 0.40 & 0.20 \\
\hline Chronic conditions, of 17 & 0.63 & 0.36 & 0.08 & -0.07 & 2.12 & 0.97 & -4.84 & 2.91 & 0.10 & -0.04 & 0.12 & 0.74 \\
\hline WOMAC global score ${ }^{\mathrm{b}}$ & -0.04 & 0.04 & 0.28 & -0.36 & 0.21 & 0.09 & -1.16 & 0.29 & $<0.001$ & -0.04 & 0.01 & $<0.001$ \\
\hline Anxiety/depressionc ${ }^{c}$ & -0.33 & 0.35 & 0.35 & -1.16 & 2.08 & 0.58 & 1.16 & 2.86 & 0.69 & -0.07 & 0.12 & 0.56 \\
\hline Total WEL score ${ }^{\mathrm{d}}$ & 0.02 & 0.02 & 0.25 & 0.12 & 0.10 & 0.22 & -0.21 & 0.14 & 0.12 & 0.00 & 0.01 & 0.63 \\
\hline Self-efficacy for exercise ${ }^{d}$ & 0.27 & 0.31 & 0.39 & 1.14 & 1.78 & 0.52 & 11.54 & 2.46 & $<0.001$ & 0.21 & 0.10 & 0.04 \\
\hline Six-minute walk, m & 0.00 & 0.01 & 0.82 & -- & -- & -- & -- & -- & -- & -- & -- & -- \\
\hline HEI-2010 & -- & -- & -- & 0.08 & 0.30 & 0.79 & 0.09 & 0.41 & 0.82 & -0.01 & 0.02 & 0.39 \\
\hline
\end{tabular}

From linear regression models with diet and physical activity variables as the dependent variable and the variables shown as independent variables. For diet data,

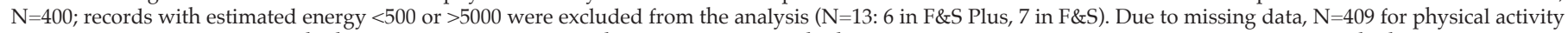

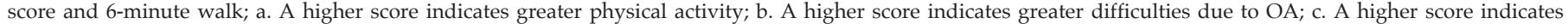
greater anxiety/depression; d. A higher score indicates greater self-efficacy.

$\mathrm{p}=.002)$, a shorter 6-minute walk distance $(\mathrm{b}=-3.38, \mathrm{p}$ $<.001)$, and fewer chair stands in 30 seconds $(b=-0.08, p$ $=.01)$. A higher BMI predicted a shorter 6-minute walk distance $(b=-4.70, p<.001)$ and fewer chair stands $(-0.08$, $\mathrm{p}=.02)$. Married participants had higher self-reported PA $(\mathrm{b}=18.44, \mathrm{p}=.009)$, but did not have significantly higher performance scores. A higher score on the WOMAC (more severe OA symptoms) predicted a shorter 6-minute walk distance $(b=-1.16, p<.001)$ and fewer chair stands $(b=-0.04, p<.001)$.

\section{Discussion}

OA is a leading cause of pain and disability among older adults in the US (43). The primary aim of this comparative effectiveness trial is to assess whether Fit \& Strong! Plus is more successful than Standard Fit \& Strong! for producing positive dietary changes at post-intervention ( 2 months) and producing a $5 \%$ or greater weight loss at 6 months that is maintained at 18 months among older adults who both have OA and are overweight or obese. The secondary aim is to assess whether Fit \& Strong! Plus will produce superior outcomes for this population in self-reported PA and physical performance, lower extremity (LE) pain, stiffness, function, anxiety/depression, and self-efficacy at 2 months that are maintained at 6,12 , and 18 months.

Dietary intake is a central aspect of weight management, and high fat consumption is a key contributor to the obesity epidemic $(44,45)$. Overall, participants in our study consumed more than the recommended amount of fat and less than the recommended amount of fiber (46). Although clinical guidelines recommend PA as a central tenet of treating OA, PA in this population is low, with less than $50 \%$ meeting current recommended activity levels (47-49). In addition, a number of articles demonstrate that African Americans are less likely to meet PA guidelines than non-Hispanic whites $(50,51)$, and that African-American women, in particular, are among those reporting the lowest levels of PA (52-54).

We also administered the performance-based sixminute walk test. The mean score in our sample was 356.3 meters, which was lower than reports from other samples comprising individuals with OA (55).

Measuring lower body strength is vital when evaluating the functional performance of older adults with OA $(34,56)$ The 30 -second chair stand test provides a reliable and valid indication of lower body strength and function (57). In our study, the mean score on this test was $8.7(\mathrm{SD}=3.6)$, which is lower than the 13.1 reported in another study of healthy older adults (mean $=70.5$ years) (34), and importantly, it was also lower than a score of 10.0 reported in a study of older adults (mean = 56.3 years) with $\mathrm{OA}(55)$.

Overall, OA-related pain and functional limitations are known to be higher among African Americans compared to non-Hispanic whites $(58,59)$. On the WOMAC, we observed both commonalities and differences between our sample and other older adult samples. For example, pain and physical function scores were 6.5 and 24.2 in the Messier IDEA trial respectively (20), compared to our 
scores of 5.6 and 18.0. Wilcox and colleagues (55) reported lower scores than our sample on the pain subscale (4.64.9), but higher scores on the stiffness subscale (5.1-5.5 vs. 3.2 in our sample). A prior study of customary Fit \& Strong! that included approximately $47 \%$ African Americans (42) reported similar scores on the pain and stiffness subscales but a higher score on physical function (42).

The differences between our older and younger participants are striking for the WOMAC. On all subscales, younger participants (60-69 years) reported more pain, stiffness, and disability than older participants ( $\geq 70$ years). This could reflect societal changes in how people think about their health, with younger groups of older adults having higher expectations for their health [60].

Limitations. The current study has several limitations. It is limited to individuals who are overweight and obese $\left(B M I=25-50 \mathrm{~kg} / \mathrm{m}^{2}\right)$ and will not provide information on how Fit \& Strong! Plus could benefit those with a $\mathrm{BMI}<25$ or $>50$. We also did not clinically confirm OA, but instead used self-reported LE pain and stiffness. Additionally, our sample consisted of primarily lowerincome adults with a median income of $\$ 25,000$.

Conclusions. This study adds to the limited literature on combined PA and diet and weight management studies with older African-American adults with OA. Our results highlight some differences in self-reported versus performance-based functioning in our study sample at baseline and also documents differences between younger and older individuals within our older adult sample. Our findings regarding increased BMI and poorer selfreported function agree with findings from several recent longitudinal studies on aging that document disturbing trends of increased disability related to overweight/ obesity in younger cohorts of aging adults $(61,62)$. These findings illustrate the need for additional research and ongoing refinement of interventions for this population that is both high-risk and growing rapidly.

\section{Author's Note}

This project is supported by Grant Number R01AG039374 from the National Institute on Aging. Additional support was provided by the American Cancer Society of Illinois grant (\#261775) and American Cancer Society Mentored Research Scholar grant MRSG014-025-01-CNE) to Dr. Lisa Tussing-Humphreys. The content of this manuscript is solely the responsibility of the authors and does not necessarily represent the official views of the National Institute on Aging or National Institutes of Health. We wish to thank Colleen Lammel and the supportive staff at the Chicago Park Districts. We would also like to thank Mirjana Antonic for her administrative support and the study participants for giving their time generously to the project.
Conflict of Interests: The authors declare that there are no conflicts of interest.

Ethical standards: All authors in this manuscript declare that they have no conflicting interest

\section{References}

1. Trends in aging - united states and worldwide MMWR Suppl. 2003;52:101-6.

2. Kington RS, Smith JP. Socioeconomic status and racial and ethnic differences in functional status associated with chronic diseases. Am J Public Health. 1997;87(5):805-10

3. Dunlop DD, Manheim LM, Sohn MW, Liu X, Chang RW. Incidence of functional limitation in older adults: The impact of gender, race, and chronic conditions. Arch Phys Med Rehabil. 2002;83(7):964-71.

4. Helmick CG, Lawrence RC, Pollard RA, Lloyd E, Heyse SP. Arthritis and other rheumatic conditions: Who is affected now, who will be affected later? National arthritis data workgroup. Arthritis Care Res. 1995;8(4):203-11.

5. Clark MM, Cargill BR, Medeiros ML, Pera V. Changes in self-efficacy following obesity treatment. Obes Res. 1996;4(2):179-81.

6. Silverwood V, Blagojevic-Bucknall M, Jinks C, Jordan JL, Protheroe J, Jordan KP. Current evidence on risk factors for knee osteoarthritis in older adults: A systematic review and meta-analysis. Osteoarthritis Cartilage. 2015;23(4):50715.

7. Szoeke CE, Cicuttini FM, Guthrie JR, Clark MS, Dennerstein L. Factors affecting the prevalence of osteoarthritis in healthy middle-aged women: Data from the longitudinal melbourne women's midlife health project. Bone. 2006;39(5):1149-55.

8. Washburn RA, Smith KW, Jette AM, Janney CA. The physical activity scale for the elderly (pase): Development and evaluation. J Clin Epidemiol. 1993;46(2):153-62.

9. Flegal KM, Kruszon-Moran D, Carroll MD, Fryar CD, Ogden CL. Trends in obesity among adults in the united states, 2005 to 2014. Jama. 2016;315(21):2284-91.

10. Freedman DS. Obesity - united states, 1988-2008. MMWR Suppl. 2011;60(1):73-7.

11. Crowninshield RD, Rosenberg AG, Sporer SM. Changing demographics of patients with total joint replacement. Clin Orthop Relat Res. 2006;443:266-72.

12. Leininger RE, Knox CL, Comstock RD. Epidemiology of 1.6 million pediatric soccer-related injuries presenting to us emergency departments from 1990 to 2003. Am J Sports Med. 2007;35(2):288-93.

13. Deshpande BR, Katz JN, Solomon DH, Yelin EH, Hunter DJ. Number of persons with symptomatic knee osteoarthritis in the us: Impact of race and ethnicity, age, sex, and obesity. Arthritis Care Res (Hoboken). 2016;68(12):1743-50.

14. Zhang W, Robertson J, Jones AC, Dieppe PA, Doherty M. The placebo effect and its determinants in osteoarthritis: Meta-analysis of randomised controlled trials. Ann Rheum Dis. 2008;67(12):1716-23.

15. March L, Amatya B, Osborne RH, Brand C. Developing a minimum standard of care for treating people with osteoarthritis of the hip and knee. Best Pract Res Clin Rheumatol. 2010;24(1):121-45.

16. Gay C, Chabaud A, Guilley E, Coudeyre E. Educating patients about the benefits of physical activity and exercise for their hip and knee osteoarthritis. Systematic literature review. Ann Phys Rehabil Med. 2016;59(3):174-83.

17. Messier SP, Loeser RF, Miller GD, Morgan TM, Rejeski WJ, Sevick MA, et al. Exercise and dietary weight loss in overweight and obese older adults with knee osteoarthritis: The arthritis, diet, and activity promotion trial. Arthritis Rheum. 2004;50(5):1501-10.

18. Messier SP, Loeser RF, Mitchell MN, Valle G, Morgan TP, Rejeski WJ, et al Exercise and weight loss in obese older adults with knee osteoarthritis: A preliminary study. J Am Geriatr Soc. 2000;48(9):1062-72

19. Villareal DT, Chode S, Parimi N, Sinacore DR, Hilton T, Armamento-Villarea $\mathrm{R}$, et al. Weight loss, exercise, or both and physical function in obese older adults. N Engl J Med. 2011;364(13):1218-29.

20. Messier SP, Mihalko SL, Legault C, Miller GD, Nicklas BJ, DeVita P, et al. Effects of intensive diet and exercise on knee joint loads, inflammation, and clinical outcomes among overweight and obese adults with knee osteoarthritis: The idea randomized clinical trial. Jama. 2013;310(12):1263-73.

21. Somers TJ, Blumenthal JA, Guilak F, Kraus VB, Schmitt DO, Babyak MA, et al. Pain coping skills training and lifestyle behavioral weight management in patients with knee osteoarthritis: A randomized controlled study. Pain. 2012;153(6):1199-209.

22. Messier SP, Gutekunst DJ, Davis C, DeVita P. Weight loss reduces knee-joint loads in overweight and obese older adults with knee osteoarthritis. Arthritis Rheum. 2005;52(7):2026-32.

23. Zinn C, Schofield GM, Hopkins WG. A "small-changes" workplace weight loss and maintenance program: Examination of weight and health outcomes. J Occup Environ Med. 2012;54(10):1230-8.

24. Fitzgibbon ML, Stolley M, Schiffer L, Sharp L, Singh V, Van Horn L, et al. Obesity reduction black intervention trial (orbit): Design and baseline characteristics. J Womens Health (Larchmt). 2008;17(7):1099-110.

25. Fitzgibbon ML, Stolley MR, Schiffer L, Sharp LK, Singh V, Dyer A. Obesity 
reduction black intervention trial (orbit): 18-month results. Obesity (Silver Spring). 2010;18(12):2317-25.

26. Stolley MR, Fitzgibbon ML, Schiffer L, Sharp LK, Singh V, Van Horn L, et al Obesity reduction black intervention trial (orbit): Six-month results. Obesity (Silver Spring). 2009;17(1):100-6.

27. Hughes SL, Seymour RB, Campbell R, Pollak N, Huber G, Sharma L. Impact of the fit and strong intervention on older adults with osteoarthritis. Gerontologist. 2004;44(2):217-28.

28. Hughes SL, Seymour RB, Campbell RT, Desai P, Huber G, Chang HJ. Fit and strong!: Bolstering maintenance of physical activity among older adults with lower-extremity osteoarthritis. Am J Health Behav. 2010;34(6):750-63.

29. Hughes SL, Seymour RB, Campbell RT, Huber G, Pollak N, Sharma L, et al. Long-term impact of fit and strong! On older adults with osteoarthritis. Gerontologist. 2006;46(6):801-14.

30. Smith-Ray RL, Fitzgibbon ML, Tussing-Humphreys L, Schiffer L, Shah A, Huber GM, et al. Fit and strong! Plus: Design of a comparative effectiveness evaluation of a weight management program for older adults with osteoarthritis. Contemp Clin Trials. 2014;37(2):178-88.

31. Block G, Hartman AM, Dresser CM, Carroll MD, Gannon J, Gardner L. A data-based approach to diet questionnaire design and testing. Am J Epidemiol. 1986;124(3):453-69.

32. Guenther PM, Casavale KO, Reedy J, Kirkpatrick SI, Hiza HA, Kuczynski $\mathrm{KJ}$, et al. Update of the healthy eating index: Hei-2010. J Acad Nutr Diet. 2013;113(4):569-80.

33. Washburn RA, McAuley E, Katula J, Mihalko SL, Boileau RA. The physical activity scale for the elderly (pase): Evidence for validity. J Clin Epidemiol. 1999;52(7):643-51.

34. Jones CJ, Rikli RE, Beam WC. A 30-s chair-stand test as a measure of lower body strength in community-residing older adults. Res Q Exerc Sport. 1999;70(2):113-9.

35. Kennedy DM, Stratford PW, Wessel J, Gollish JD, Penney D. Assessing stability and change of four performance measures: A longitudinal study evaluating outcome following total hip and knee arthroplasty. BMC Musculoskelet Disord. 2005;6:3.

36. Naylor JM, Hayen A, Davidson E, Hackett D, Harris IA, Kamalasena G, et al. Minimal detectable change for mobility and patient-reported tools in people with osteoarthritis awaiting arthroplasty. BMC Musculoskelet Disord. 2014; 15:235.

37. Guyatt GH, Sullivan MJ, Thompson PJ, Fallen EL, Pugsley SO, Taylor DW, et al. The 6-minute walk: A new measure of exercise capacity in patients with chronic heart failure. Can Med Assoc J. 1985;132(8):919-23.

38. Hughes SL, Edelman P, Chang RW, Singer RH, Schuette P. The geri-aims Reliability and validity of the arthritis impact measurement scales adapted for elderly respondents. Arthritis Rheum. 1991;34(7):856-65.

39. Dutton GR, Martin PD, Rhode PC, Brantley PJ. Use of the weight efficacy lifestyle questionnaire with african american women: Validation and extension of previous findings. Eat Behav. 2004;5(4):375-84.

40. Skou ST, Wise BL, Lewis CE, Felson D, Nevitt M, Segal NA. Muscle strength, physical performance and physical activity as predictors of future knee replacement: A prospective cohort study. Osteoarthritis Cartilage. 2016;24(8):1350-6.

41. Martin KA, Rejeski WJ, Miller ME, James MK, Ettinger WH, Jr., Messier SP. Validation of the pase in older adults with knee pain and physical disability. Med Sci Sports Exerc. 1999;31(5):627-33.

42. Pinto BM, Clark MM, Cruess DG, Szymanski L, Pera V. Changes in selfefficacy and decisional balance for exercise among obese women in a weight management program. Obes Res. 1999;7(3):288-92.

43. Johnson VL, Hunter DJ. The epidemiology of osteoarthritis. Best Pract Res Clin Rheumatol. 2014;28(1):5-15.

44. Fung TT, Rimm EB, Spiegelman D, Rifai N, Tofler GH, Willett WC, et al.
Association between dietary patterns and plasma biomarkers of obesity and cardiovascular disease risk. Am J Clin Nutr. 2001;73(1):61-7.

45. Cordain L, Eaton SB, Sebastian A, Mann N, Lindeberg S, Watkins BA, et al. Origins and evolution of the western diet: Health implications for the 21st century. Am J Clin Nutr. 2005;81(2):341-54.

46. Dietary guidelines for americans, 2010. Washington, D.C.: Office of Disease Prevention and Health Promotion, 2010 December 2010. Report No.

47. Holden MA, Nicholls EE, Young J, Hay EM, Foster NE. Exercise and physical activity in older adults with knee pain: A mixed methods study. Rheumatology (Oxford). 2015;54(3):413-23.

48. Herbolsheimer F, Schaap LA, Edwards MH, Maggi S, Otero A, Timmermans EJ, et al. Physical activity patterns among older adults with and without knee osteoarthritis in six european countries. Arthritis Care Res (Hoboken). 2016;68(2):228-36

49. Wallis JA, Webster KE, Levinger P, Taylor NF. What proportion of people with hip and knee osteoarthritis meet physical activity guidelines? A systematic review and meta-analysis. Osteoarthritis Cartilage. 2013;21(11):1648-59.

50. Mama SK, McNeill LH, McCurdy SA, Evans AE, Diamond PM, AdamusLeach HJ, et al. Psychosocial factors and theory in physical activity studies in minorities. Am J Health Behav. 2015;39(1):68-76.

51. Matthews CE, Chen KY, Freedson PS, Buchowski MS, Beech BM, Pate RR, et al. Amount of time spent in sedentary behaviors in the united states, 20032004. Am J Epidemiol. 2008;167(7):875-81.

52. Tucker JM, Welk GJ, Beyler NK. Physical activity in u.S.: Adults compliance with the physical activity guidelines for americans. Am J Prev Med. 2011;40(4):454-61.

53. Troiano RP, Berrigan D, Dodd KW, Masse LC, Tilert T, McDowell M. Physical activity in the united states measured by accelerometer. Med Sci Sports Exerc 2008;40(1):181-8.

54. Cohen SS, Matthews CE, Signorello LB, Schlundt DG, Blot WJ, Buchowski MS. Sedentary and physically active behavior patterns among low-income african-american and white adults living in the southeastern united states. PLoS One. 2013;8(4):e59975.

55. Wilcox S, McClenaghan B, Sharpe PA, Baruth M, Hootman JM, Leith K, et al. The steps to health randomized trial for arthritis: A self-directed exercise versus nutrition control program. Am J Prev Med. 2015;48(1):1-12.

56. Stump TE, Clark DO, Johnson RJ, Wolinsky FD. The structure of health status among hispanic, african american, and white older adults. J Gerontol B Psychol Sci Soc Sci. 1997;52 Spec No:49-60.

57. Bohannon RW. Sit-to-stand test for measuring performance of lower extremity muscles. Percept Mot Skills. 1995;80(1):163-6.

58. Anderson KO, Green CR, Payne R. Racial and ethnic disparities in pain: Causes and consequences of unequal care. J Pain. 2009;10(12):1187-204.

59. Hardt J, Jacobsen C, Goldberg J, Nickel R, Buchwald D. Prevalence of chronic pain in a representative sample in the united states. Pain Med. 2008;9(7):80312.

60. Martin LG, Freedman VA, Schoeni RF, Andreski PM. Health and functioning among baby boomers approaching 60. J Gerontol B Psychol Sci Soc Sci. 2009;64(3):369-77.

61. Rosen DMCaELGaAB. Is the us population behaving healthier? Working Paper. National Bureau of Economic Research, 2007 April. Report No.: Contract No.: 13013.

62. Olshansky SJ. Projecting the future of u.S. Health and longevity. Health Aff (Millwood). 2005;24 Suppl 2:W5r86-9. 